\title{
Cien años de la traducción de los Cuentos de los hermanos Grimm en China: recepción y manipulación
}

Jinwei Wang ${ }^{1}$ y Yang Song ${ }^{2}$

Recibido: 5 de septiembre de 2016 / Aceptado: 17 de enero de 2017

Resumen. Este trabajo presenta brevemente la historia de la traducción de los Cuentos de los hermanos Grimm en China así como sus traductores destacables. Se divide esta centenaria historia en cuatro etapas: inicio, desarrollo, madurez y modernización. También se describe cómo la traducción de los Cuentos en China alcanzó en tres momentos cruciales un considerable apogeo.

Palabras clave: Cuentos de Grimm, traducción, recepción, manipulación, China.

\section{One Hundred Years of Translation of Grimm's Fairy Tales in China: Reception and Manipulation}

\begin{abstract}
This paper presents the history of the translation of Grimms' Fairy Tales as well as its outstanding translators in China. We not only divide this centennial history into four stages: initiation, development, maturity and modernization, and also describe how the translation of the Grimms' Fairy Tales in China reached on three crucial moments a considerable height.

Keywords: Grimm brothers' fairytales, translation, reception, manipulation, China.
\end{abstract}

Sumario: 1. Introducción. 2. Etapa de inicio: traducción parcial de los Cuentos. 3. Etapa de desarrollo: traducción completa de los Cuentos. 4. Etapa de madurez: gran interés por los Cuentos. 5. Etapa de modernización: didáctica de lenguas extranjeras con los Cuentos. 6. Influencias de los Cuentos de Grimm en China. 7. Conclusiones.

Cómo citar: Jinwei, W., Yang, S. (2017) Cien años de la traducción de los Cuentos de los hermanos Grimm en China: recepción y manipulación, en Estudios de Traducción 7, 39-47.

\section{Introducción}

Desde la segunda mitad del siglo XIX las potencias occidentales pretendieron conquistar varios países asiáticos. Después de la Guerra del Opio (1839-1842) entre

\footnotetext{
$1 \quad$ Universidad de Estudios Extranjeros de Pekín wangjinwei@bfsu.edu.cn

2 Universidad de Pekín yang.song@pku.edu.cn
} 
China y Gran Bretaña — que marcó el inicio de la época humillante de la historia de China - tuvieron lugar sucesivas guerras contra países extranjeros, cuyas consecuencias fueron la derrota del país, la obligada cesión de territorios y puertos marítimos a las potencias extranjeras, y la firma de tratados desventajosos mediante los que se indemnizaba a los países invasores. En este contexto sociopolítico frustrante, los intelectuales chinos empezaron a reflexionar sobre cómo podrían salvaguardar la soberanía: surgieron voces que clamaban por la reforma de la tradición, pero la mayoría coincidía en un punto: el anhelo de modernización, encarnado en "lo extranjero". El deseo de occidentalización que albergaban los intelectuales otorgaba a la traducción un papel fundamental para la reconstrucción nacional (Tai, 2012: 159). De este modo, algunos escritores consideraban que mediante la traducción de literatura extranjera se podía impulsar la literatura y la lengua. De ahí que la traducción se convirtiera en el vehículo necesario para el fomento de la tradición literaria y para hacer de la lengua clásica la fuente de nuevas transformaciones. A finales del siglo XIX y principios del XX en China, muchos intelectuales desempeñaban el doble papel de escritores y traductores en su labor creadora; entre ellos destacaron Zhou Guisheng y Zheng Guangong.

\section{Etapa de inicio: traducción parcial de los Cuentos}

\subsection{Zhou Guisheng y Zheng Guangong: traductores pioneros}

Zhou Guisheng fue el primer traductor que introdujo los Cuentos de los hermanos Grimm a los lectores chinos. Nacido en Shanghái - la entonces concesión extraterritorial $^{3}$ de Francia, Gran Bretaña y Alemania - estudió en un colegio occidental y optó por el francés como su especialidad y el inglés como segunda lengua extranjera. Posteriormente, trabajó en la Radio de Tianjin como interlocutor de francés y se desempeñó como gerente de una empresa inglesa de embarcación en Shanghái. Asimismo, realizó varios viajes de negocios en países desarrollados de Europa. Por todas estas experiencias particulares, adquirió una perspectiva amplia del mundo europeo así como una elevada competencia lingüística en francés e inglés. En 1902 publicó en el Periódico de Fábulas [寓言报] doce cuentos ${ }^{4}$ de los hermanos Grimm: él estaba convencido de que, con la ayuda de estas traducciones, podría abrir la mente al pueblo y salvar la nación. Esta idea suya se hace evidente en su introducción de los textos donde advierte:

[el emperador] ha decidido dar comiendo al movimiento de reforma y los ciudadanos también muestran gran esperanza y están dispuestos a iniciar un fortalecimiento y una modernización a su país. Al estudiar y analizar la situación actual de China, los estudiosos patriotas consideran que es imposible llegar a ser un Estado

\footnotetext{
3 Las concesiones extraterritoriales de China eran territorios arrendados o cedidos a otro país (o a varios, como en el caso de Shanghái) a través de tratados desiguales durante la época colonial (s. XVIII-s. XIX).

4 Los doce cuentos son: "El ratón y el gato asociados", "El lobo y las siete cabritas", "El músico prodigioso", "El rey rana", "Los tres enanitos del bosque", "Los doce hermanos", "La zorra y los gansos", "El señor Korbes", "La zorra y el gato", "Piel de oso", "Monte Simelí", "Las princesas bailadoras".
} 
avanzado si no se introducen elementos fundamentales de culturas más adelantadas. Por ello, el primer paso deberá consistir en traducir obras de lenguas extranjeras $[\ldots]$

Para alcanzar este objetivo, la estrategia más eficaz de la que se podía valer un traductor consistía en adaptar el texto original según su propio juicio y redactar comentarios de acuerdo con su punto de vista (Zhou, 1905: 20). Si nos fijamos en los doce cuentos publicados, encontraremos que ocho poseen tal comentario. Veamos a continuación dos ejemplos.

En el caso de "El ratón y el gato asociados", el traductor asevera en su comentario:

El hecho de que el ratón trate de ser socio del gato equivale a cuando los países débiles intentan mantener una relación amistosa con los países avanzados: al final resultarán invadidos y devorados (Zhou, 1902: 7).

En el comentario de "El lobo y las siete cabritas", dice:

El lobo es avaricioso y sin duda alguna morir en terrible sufrimiento es su único destino. Pero, ¿acaso no han de ser castigados sus cómplices, el tahonero y el molinero? Quien ayuda a un tirano a hacer el mal debe ser castigado igualmente (Zhou, 1902: 10).

Cabe mencionar que estos cuentos fueron redactados en chino clásico y se tradujeron del francés o del inglés ( $\mathrm{Hu}, 1999: 49)$. Gracias a ello los lectores chinos tuvieron la oportunidad de leer por primera vez cuentos que, en ese momento, pudieron considerarse exóticos.

Otro traductor que hizo trabajos fundamentales fue Zheng Guangong; de él, lamentablemente, no han sobrevivido datos biográficos, ni siquiera su fecha de nacimiento. Solo disponemos de textos publicados bajo su nombre. En la 东方杂志 [Revista de Oriente], de los números VII a XIII de 1909 y de I a XII de 1910 aparecieron publicados cuarenta y ocho cuentos de los hermanos Grimm. Zheng hizo las traducciones por el mismo motivo que Zhou, pues en la introducción dice que los cuentos "tanto favorecen a la política como benefician al pueblo" (Zheng, 1909: 11).

Los dos traductores realizaron trabajos pioneros en la historia de la traducción de los cuentos de Grimm en China. Sin embargo, debido a que el idioma de destino que usaban era el chino clásico (o sea la variante culta de la lengua), sus trabajos no estaban dedicados a lectores populares sino a gente con estudios y a la clase social con una misión política.

\subsection{Sun Yuxiu y Mao Dun: traducciones al chino popular}

Sun Yuxiu (1871-1923), escritor y editor, coordinó de 1918 a 1920 la publicación de setenta y siete fascículos coleccionable bajo el título de Cuentos, con la ayuda de Mao Dun (1896-1981). Durante este periodo, los dos publicaron continuamente cuentos de Anderson y de Grimm. La contribución más relevante que hicieron consistió en traducir los cuentos al chino popular y adaptarlos para niños de modo que sirvieran como lectura en la primaria. Dice el coordinador en el prólogo que los 
cuentos de cada volumen son muy variados desde la perspectiva de la dificultad de la lengua y de la extensión del texto. Es decir, los textos aumentan el nivel de dificultad en relación con el progreso lingüístico de los lectores. Además, se añadieron dibujos para que resultaran más llamativos. Para los niños de entre siete y ocho años ofrecían libros de dieciséis cuentos en cada volumen, con cinco mil caracteres por texto; para los mayores, entre diez y once años, libros de treinta y dos cuentos y diez mil caracteres por cada texto. Esto (de)muestra que ya era consciente de que para niños de distintas edades habría que diseñar lecturas de diferentes niveles. Asimismo, en el proceso de elaboración de los textos, una vez terminada una traducción, la leía a sus hijos y si había algo que no les hiciera gracia, lo cambiaba. Así pues, resulta evidente que Sun ya daba prioridad a la enseñanza de los niños con estas lecturas adaptadas y este representa el primer paso documentado de la China contemporánea en cuanto a educación infantil.

\subsection{Wang Shaoming: traducciones del alemán}

Otro trabajo significativo fue el de Wang Shaoming (1883-1951), el primero en traducir los Cuentos de los hermanos Grimm directamente del alemán. Decidió realizar este trabajo considerando que todas las traducciones anteriores fueron realizadas a partir del francés o del inglés. Al leer a los otros traductores, lamenta que en las traducciones chinas el texto no corresponda al texto original. Sospechaba que o bien los traductores habrían modificado el texto con alguna intención, o bien lo traducían desde otras lenguas intermedias ${ }^{5}$. Por lo tanto, decide rehacer este trabajo con el propósito de presentar al público traducciones más “fieles". En 1925 apareció la primera tirada en el mercado chino de la traducción de Kinder und Hausmarchen der Bruder Grimm compuesta por cincuenta cuentos.

\subsection{Zhao Jingshen y Zhou Zuoren: traductores e investigadores}

Zhao Jingshen (1902-1985) fue un escritor, historiador y traductor que a mediados de los años veinte del siglo pasado empezó a traducir los Cuentos de los hermanos Grimm. Hacia los años cuarenta tenía ya publicados treinta y ocho textos en total. Aparte de esto, también se dedicaba a la investigación estilística de los cuentos literarios extranjeros. Publicó Introducción al cuento literario (1927) y Abecedario del cuento literario (1929) con el propósito de presentar a los investigadores chinos una teoría del cuento literario del mundo europeo. Mientras tanto, estudió las similitudes y diferencias entre los cuentos chinos y extranjeros desde el punto de vista de la literatura comparada, y aportó nuevas orientaciones para el desarrollo de la literatura infantil en China.

Otro investigador relevante en este campo es Zhou Zuoren (1885-1967). En 1913 publicó trabajos como Investigación del cuento literario y Breve comentario de cuentos literarios. Las charlas que sostuvo con Zhao sobre el tema de los cuentos fueron publicadas en el suplemento del Periódico de la Mañana [晨报]. Ambos discutieron la etimología de la palabra 童话 (tónghuà, “cuento" en chino) y, a partir de 
ahí, plantearon la definición, la función y las propiedades de los cuentos infantiles. Un dato curioso es que tanto Shen como Zhao consideraban, en aquella época, que los cuentos de los hermanos Grimm eran - en comparación con los cuentos de Anderson y de Oscar Wilde - más convenientes para el progreso psíquico de los niños (Wang, 2008).

Antes de 1934 otros traductores también habían participado en la tarea de la traducción parcial de la obra de los hermanos Grimm. Periódicos, revistas y libros fueron sus terrenos y, así, la traducción de Grimm llegó por primera vez a su apogeo durante los años veinte y treinta del siglo pasado.

\section{Etapa de desarrollo: traducción completa de los Cuentos}

En 1934, treinta años más tarde de la primera publicación de los Cuentos de los hermanos de Grimm, Wei Yixin (1902-1974) publicó por primera vez la traducción completa de los doscientos diez cuentos de Grimm a partir del alemán, lo cual representa un avance histórico. En el prólogo el traductor dice (Wei, 1934: 2):

Esta obra proviene de los Cuentos de los hermanos Grimm publicados por Hesse\&Becker Verlag, Leipzig. De los doscientos diez cuentos que contiene, veintiuno fueron escritos en dialectos del alemán (en cuyos títulos se ha puesto un *) y no los entienden ni el sesenta por ciento de los alemanes nativos. A pesar de ello, gracias a que el traductor trabajaba como ayudante del Prof. Dr. Othmer, quien le ha brindado detalladas explicaciones, ha conseguido llevar a buen fin esta tarea. Se agradece aquí tan inmensa ayuda. ${ }^{6}$

La primera tirada alcanzó un gran éxito y se publicaron nuevas ediciones en 1947, 1956, 1959 y 1978. Además de Wei, traductores como Lin Junqian (19101968), Zhang Yipeng (1909-1978) y Feng Huazhan (1924-2001) también publicaron una colección completa de los cuentos en 1940, 1949 y 1951 respectivamente. Posteriormente, durante los años sesenta y setenta, debido a la marejada política que supuso la Revolución Cultural, todos los trabajos relacionados con lenguas extranjeras se detuvieron y, consecuentemente, la traducción y la publicación de los Cuentos de Grimm también cesó.

\section{Etapa de madurez: gran interés por los Cuentos}

En la década de los ochenta, al terminar la catástrofe política, la gente mostraba una gran curiosidad e interés por la literatura extranjera tras más de diez años de silencio (Zou, 2001). Desde ese momento se ha prestado mucha importancia a la traducción de los Cuentos de los hermanos Grimm y, de manera general, se ha observado una notable prosperidad en este campo, es decir, coexisten numerosas traducciones diversas. Entre todos los traductores de este periodo Yang Wuneng (1938- ) es el más relevante.

Texto original: 这部《格林童话全集》系根据Leipzig, Hesse\&Becker Verlag德国名著从书版本译出。共 二百一十篇, 内有二十一篇是用德国方言写的（在目录上加以*标记），德人亦有十分之六不能完全 了解, 然译者因为日夕在业师德国语言学家欧特曼教授（Prof. Dr. Othmer）手下工作，竟得因其口授 而完全译出, 颇以为幸! 此外, 欧教授又为译者揭示其他各种疑难, 谨此表示极诚恳之谢意! 
Yang se licenció en filología alemana por la Universidad de Nanjing y luego trabajó en la Universidad de Sichuan como profesor de alemán. Ha traducido muchas obras literarias alemanas, en particular las de Goethe. En 1993 publicó la traducción completa de los Cuentos de los hermanos Grimm a partir de la obra editada en Stuttgart en 1989. Desde la primera tirada alcanzó a un gran público y se reeditó de nuevo en 1994, 1996, 1999, 2000, 2003, 2007, etc. Muchos cuentos traducidos han sido seleccionados como material docente para niños en la educación primaria y para adolescentes en la secundaria. En 2000 le otorgaron la Condecoración de la República Federal Alemana por una obra que ha contribuido a promover notablemente el contacto intercultural entre China y Alemania.

Por otro lado, cabe mencionar que en esta década cinco editoriales reeditaron la traducción de Wei Yixin que discutimos anteriormente.

\section{Etapa de modernización: didáctica de lenguas extranjeras con los Cuentos}

A partir de la década de los noventa, bajo el contexto sociopolítico de la globalización económica, en China se brinda cada día mayor atención a la enseñanza de lenguas extranjeras (en particular el inglés). En todas las universidades se ofrece la carrera de Filología Inglesa - téngase en cuenta que en China hay unas mil universidades públicas y unas setecientas universidades privadas - aunque con distintas orientaciones de enseñanza. De tal forma, durante este tiempo se dio mucho impulso a la publicación de ediciones bilingües: chino-inglés, chino-francés, chino-alemán, etc.

Por otro lado, han surgido también publicaciones de las nuevas generaciones. Por comparación con los libros tradicionales, los nuevos volúmenes suelen incluir gran número de imágenes, casete, CDs o DVDs. Muchos se venden acompañados de muñecos de los personajes, o de libretas para pintar los personajes, etc.

A la fecha, hemos podido documentar más de cien ediciones de los Cuentos de Grimm. La mayoría de ellas han sido traducidos a partir de inglés, japonés y ruso, y solo diez provienen directamente del alemán. Todos estos cuentos tienen versiones adaptadas para lectores de cualquier edad, desde versiones de dibujos para niños de dos años hasta textos cabalmente literarios para lectores adultos e investigadores.

\section{Influencias de los Cuentos de Grimm en China}

Ha transcurrido un siglo desde que la primera traducción de los Cuentos de los hermanos Grimm se publicó en China. A partir de los últimos años de la dinastía Qing hasta la primera parte del siglo Xx, la traducción de estos cuentos desempeñó un papel muy importante en el desarrollo y la modernización de China. A continuación analizamos dos ejemplos de esta influencia.

\subsection{Favorecimiento del nacimiento de la literatura infantil}

Durante muchos siglos de la historia china se pasó por alto la literatura infantil, es decir, hubo pocas obras dedicadas solamente a los niños. Si bien se leía mucho entre los niños el Clásico de tres caracteres [三字经], los Cuentos históricos infantiles [ 
龙文鞭影], los Cuentos del tesoro del conocimiento infantil [幼学琼林], entre otros, estas son obras clásicas del confucianismo, que transmiten básicamente las doctrinas morales y religiosas predicadas por los discípulos y seguidores de Confucio. En lugar de tratar a los niños como seres humanos en una situación especial, ${ }^{7}$ los consideraban como adultos en miniatura (Du, 2012: 99) y procuraban convertirlos en creyentes y seguidores fieles de esa religión, sin tener en cuenta sus necesidades peculiares y específicas. Desde finales de la dinastía Qing - al principio del siglo $\mathrm{XX}$-, en el proceso de mirar hacia fuera y aprender de los extranjeros, los traductores empezaron a darse cuenta de que la educación específicamente infantil resultaba una parte imprescindible del futuro del país y de que los libros apropiados para los niños constituirían el material docente fundamental. Basándose en esta idea, Zhou Zuoren, Sun Yuxiu, Zhao Jingsheng, Mao Dun, etc. dieron inicio a la traducción y a la composición de cuentos infantiles en China.

Con el apogeo de la traducción de los Cuentos de los hermanos Grimm, llegó simultáneamente la perspectiva moderna de Europa hacia los niños y el concepto de la literatura infantil, lo que llevó a numerosos autores a reconocer la existencia de una mentalidad específica de los niños y crear obras de lectura para ellos. En 1920 Zhou Zuoren publicó un estudio titulado Literatura infantil [儿童的文学] en el que hacía hincapié en el valor y la importancia de esta variedad literaria; este estudio anuncia el nacimiento de la literatura infantil en China.

\subsection{Promotor de la protección a la literatura popular}

En China se publicaban cuantiosas obras literarias populares y folclóricas, pero esta situación cambió en el año 134 a. C., cuando el entonces emperador Han Wudi aceptó la propuesta de descartar las otras escuelas y reverenciar solamente la confuciana [罢黜百家, 独尊儒术], con la finalidad de convertir el confucianismo en la única ideología dominante. A partir de ese momento y hasta finales de la última dinastía, las obras confucianas siempre aventajaron a las otras.

La llegada de los Cuentos de Grimm a China llamó la atención de diversos autores e investigadores de la literatura popular. Hu Yuzhi (1921: 15) señaló que los Cuentos de los hermanos Grimm "poseen una visión vanguardista" y debido a los dos hermanos:

Cada día más investigadores se dedican al estudio y recopilación de los cuentos folclóricos, y asimismo, más trabajos de investigación y colecciones de este campo se han llevado a ser publicados. [...] sin embargo, en nuestro país nunca se han compilado cuentos, poemas, leyendas, etc.

Como conclusión de esta circunstancia exhortaba al gobierno a que fundase la "Academia de Estudios Folclóricos" para "reunir esos valiosos materiales de forma moderna y científica" (Hu, 1921: 18). Gracias a sus palabras, Hu Shi, Zhou Zuoren, Liu Bannong, Shen Yimo así como otros muchos escritores comenzaron a dar los

Es preciso subrayar la importancia que tiene en la niñez la complementación del potencial genético, las experiencias físicas y afectivas de los primeros meses de vida y las relaciones sociales en los años posteriores. Tal es la relevancia de estos procesos en la infancia que las alteraciones en estas fases dan lugar a perturbaciones que pueden ser el punto de partida de enfermedades mentales de diversa magnitud en el futuro. 
primeros pasos en este campo. El ilustre traductor Zhao Jingshen (que ya mencionamos en el apartado 1) declaró que quería "ser un soldado en el movimiento del desarrollo de la literatura popular" (Zhao, 1927: 11). Así, en la década de 1930 se publicaron proyectos ambiciosos como Cuentos folclóricos de la Corea o Cuentos populares del Tíbet. Desde esta perspectiva resulta evidente que los Cuentos de los hermanos Grimm promovieron decididamente el estudio y la recuperación de la literatura popular.

\section{Conclusiones}

Una vez concluido este repaso de la historia de la traducción de los Cuentos de Grimm en China, podemos observar que los afanes de traducción de esta obra han alcanzado tras veces un claro apogeo. La primera ocurrió entre los años veinte y treinta cuando multitudes de estudiosos patriotas manipulaban la traducción de obras literarias de los países desarrollados para introducirlas en China y enriquecer, así, su propia cultura. Los Cuentos de los hermanos Grimm son un producto del movimiento romántico en Alemania, por lo que abordan específicos aspectos sociales, culturales y políticos. Así, en las décadas de 1920 y 1930, cuando China pasaba por una crisis nacional, los patriotas intentaron salvar a su país con una renovación cultural en la que la literatura formara una parte imprescindible. Como dice Liang Qichao $^{8}$ para renovar la mente de un pueblo, hay que renovar ante todo el pensamiento de su literatura [欲新一国之民, 不可不新一国之小说的思想]. En este sentido, la traducción de los Cuentos de Grimm representa una elección cultural y política que asumieron los estudiosos con el fin de proteger su patria y salvaguardar su independencia.

El segundo momento de auge tuvo lugar en la década de 1950 después de la fundación de la República Popular China, cuando se tradujeron los cuentos occidentales con el propósito de desarrollar la educación y la literatura infantiles que en ese momento faltaban del todo y, por lo tanto, resultaban urgentes. En la antigua China, no faltaron nunca cuentos tradicionales, pero la mayoría presentaba rasgos supersticiosos. Por ello, en el proceso del fortalecimiento de la educación infantil, el Partido Comunista, que es ateísta, prefería usar los cuentos de Grimm y Anderson como materiales.

El último clímax de creación traductológica tuvo lugar en los años noventa, cuando se publicaron multitudes de libros con cuentos bilingües (inglés-chino, alemán-chino, etc.) con contenidos diferenciados para estudiantes de todos los niveles, ya que en ese momento se dio suma prioridad al aprendizaje de lenguas extranjeras a escala nacional.

Fue un erudito, periodista, filósofo y político reformista chino que vivió durante los años finales de la dinastía Qing y los primeros años de la República. Fue el primer y emblemático intelectual moderno de China y en sus escritos combinó su saber clásico chino con una gran sensibilidad para las ideas y las tendencias occidentales. Influyó en varias generaciones de pensadores y políticos chinos.Cita en la lengua original: “国人所译 格氏兄弟的童话, ......多与原文不相符合; 不知是译者故为修改, 也不知是, 非译自原文一一外人 已有删增了。”(Wang, 1925: 1-2). 


\section{Referencias bibliográficas}

Du, R., «Los cuentos de Grimm y la literatura infantil en China» [格林童话与中国 现代儿童文学的诞生], Revista de la Universidad de Renmin 6 (2012), 99-104.

$\mathrm{Hu}$, C. J., Literatura infantil de la última etapa de la dinastía Qing [晚清儿童文学 钩沉], Shanghái: Shaonian Ertong 1999.

Hu, Y. Zh., «Estudio de la Literatura Popular» [论民间文学]. Revista del Estudio Feminista 7 (1921), 12-19.

Tai, Y. F., «La traducción literal del escritor Lu Xun (1881-1936) como impulso a la lengua vernácula (baihua) y a la nueva literatura en China», Estudios de Traducción 2 (2012), 157-166.

Zheng G. G., «Unos cuentos exóticos» [时谐], Revista de Oriente 7 (1909), 11-13.

Zhou, G. Sh., «Cuentos extranjeros» [外国故事], Periódico de Fábulas 12 (1902), 5-17.

Zhou. G. Sh., «Cuentos y novelas» [小说故事], Nuevas novelas 9 (1905): 16-24.

Zou, Z. H., Intercambios culturales y traducciones del siglo XX en Shanghái [二十 世纪上海文化翻译交流]. Nanning: Guangxi Jiaoyu 2001.

Wang, Q. G., Literatura infantil [儿童文学]. Beijing: Beifang Ertong 2008.

Wei, Y. X., Cuentos de los hermanos Grimm [格林兄弟童话]. Shangái: Shangwu 1934.

Zhao, J. Sh., Introducción al cuento literario [童话概要]. Shanghái: Beixin 1927. 